\title{
Antifungal activity of Piper cubeba L. extract on spoilage fungi isolated from tomato, grapes and lemon
}

\author{
${ }^{1,3}$ Fazly-Ann, Z., ${ }^{1}$ Nor-Hafizah, M.Y. and ${ }^{1,2 *}$ Rukayadi, Y. \\ ${ }^{1}$ Department of Food Science, Faculty of Food Science and Technology, Universiti Putra Malaysia, 43400 \\ UPM Serdang, Selangor, Malaysia \\ ${ }^{2}$ Laboratory of Natural Products, Institute of Bioscience, Universiti Putra Malaysia, 43400 UPM Serdang, \\ Selangor, Malaysia \\ ${ }^{3}$ Veterinary Research Institute, 59, Jalan Sultan Azlan Shah, 31400 Ipoh, Perak, Malaysia
}

\section{Article history:}

Received: 4 August 2019

Received in revised form: 23

August 2019

Accepted: 25 August 2019

Available Online: 12

September 2019

\section{Keywords:}

Antifungal,

Piper cubeba L.,

Geotricum candidum,

Penicillium citrinum,

Trametes hirsuta

DOI:

https://doi.org/10.26656/fr.2017.4(1).278

\begin{abstract}
The berries of Piper cubeba L. or commonly recognized as tailed pepper are traditionally used as flavoring ingredients in various types of food. It has been reported with abundant of phytochemical compounds that contribute to its nutritional and medicinal properties. The antimicrobial effect of the spice including antifungal activity was believed to reduce the potential of fungal spoilage thus minimizing food losses and wastage. This study was aimed to determine the antifungal activity of $P$. cubeba L. extract against isolated spoilage fungi namely Geotricum candidum (TMa 001), Penicillium citrinum (GRd 001) and Trametes hirsuta (LMd 001) by in vitro and in vivo techniques. Disc diffusion assay, minimum inhibitory concentration (MIC) and minimum fungicidal concentration (MFC) test of the methanolic extract were performed on the selected fungi. The largest inhibition zone, fungistatic and fungicidal effects were detected in T. hirsuta with $18.30 \pm 3.00 \mathrm{~mm}$, $0.039 \mathrm{mg} / \mathrm{mL}$ and $0.078 \mathrm{mg} / \mathrm{mL}$, respectively. The inhibition of conidial germination assay was performed at $0 \times \mathrm{MIC}, 0.5 \times \mathrm{MIC}, 1 \times \mathrm{MIC}, 2 \times \mathrm{MIC}$, and $4 \times \mathrm{MIC}$, and the result showed G. candidum were completely inhibited at $4 \times$ MIC. The ideal concentration of $P$. cubeba L. extract on different selected food commodities were $0.50 \%$ against $G$. candidium in tomato, $0.50 \%$ to $5.00 \%$ against $P$. citrinum in grapes, and $5.00 \%$ against $T$. hirsuta in lemon. The findings implied that $P$. cubeba L. extract can be listed as one of the natural antifungal agents in food. The availability of various types of natural antifungal agents will help in reducing the usage of chemical fungicide, which may lead to adverse and deteriorating health effects in the events of prolong consumption.
\end{abstract}

\section{Introduction}

Piper cubeba L. berries commonly known as tailed pepper belongs to the Piperaceae family and comes from the Piper genus. The pepper of the perennial shrub was originated from Indonesia and mostly cultivated in Java and Sumatra, and some part of India (Nahak and Sahu, 2011). Besides used as flavoring ingredients in food, the pepper have been widely reported in traditional medicines practices mainly to cure abdominal pain, asthma, intestinal disease, dysentery, bronchitis, cough, tuberculosis and rheumatism (Bos et al., 2007; Shakeel et al., 2019). The pepper is rich with the valuable phytochemical compounds such as alkaloids (piperine and cubebin), amides, flavanones, flavones, lignans, neolignans, terpenes, sesquiterpenes and propenylphenols (Parmar et al., 1997). Scientifically, the antimicrobial effect of $P$. cubeba berries such as antifungal (Rukayadi et al., 2013), antibacterial (Aneja et al., 2010; Rezende et al., 2016), antiparasitic (Esperandim et al., 2013) and antiviral (Hussein et al., 2000) has been reported in several studies.

Food spoilage is a metabolic process which involved changes in the food chemical or physical properties which caused food to be undesirable for human consumption (Gram et al., 2002). It gives economic impact by reduces the shelf life, quality and safety of food product. Approximately 5 to $10 \%$ of food losses are caused by fungal food spoilage (Pitt and Hocking, 2009). The pathogen easily penetrate and infect the plant tissue of the food, usually throughout the lesion and injury caused by improper handling of fresh produce practices (Gustavsson et al., 2011). High moisture contents and low temperature environment also provide an ambient condition for the fungal development. In perishable 
produces such as tomato, grapes and lemon, several fungal pathogens have been reported including; Aspergillus spp., Penicillium spp., Geotrichum spp., Fusarium spp., Trametes spp. and Rhizopus spp. (Birhanu et al., 2014; Cilerdzic et al., 2011; Kalyoncu et al., 2005; Tournas and Katsoudas, 2005). In tomato and grapes the fungal species such as $G$. candidum and $R$. stolonifer spoil the fruits by soft rots (Latorre et al., 2002; Samuel and Orji, 2015). Any types of spoilage defect in fruits may become the reason for postharvest losses.

Postharvest damages and unfavorable appearance due to fungal spoilage may contribute to the food wastage globally. Nowadays, spraying synthetic pesticides, adding chemical preservatives and additives are typical ways to control the fungal infection on food (Ismail and Zhang, 2004; Palou et al., 2007). However, environment and health issue has been arising, thereby becoming a public concern that needs to be considered. An alternative way to suppress the growth of food spoilage fungi needs to be discovered (Sheikh et al., 2012). Currently, the natural antifungal from plants extracts become an alternative (Cabral et al., 2013). Therefore, as the $P$. cubeba L. is recognized with antimicrobial potential, the use of the extract as natural antifungal agent is believed will minimize the occurrence of fungal spoilage in perishable produces. Thus, this study was conducted to determine the antifungal activity of $P$. cubeba L. extract against the selected spoilage fungi; G. candidum, $P$. citrinum and T. hirsuta by in vitro techniques and in its common fresh produce commodities.

\section{Materials and methods}

\subsection{Fungi preparation}

G. candidum (TMa 001), P. citrinum (GRd 001) and T. hirsuta (LMd 001) isolated from infected tomato, grapes and lemon respectively were obtained from the stock cultures in Laboratory of Natural Products, Institute of Bioscience, Universiti Putra Malaysia. The isolates were subcultured onto potato dextrose agar (PDA) media to permit growth.

\subsection{P. cubeba L. extraction}

The dried $P$. cubeba L. berries were purchased from Herbal Traditional Market, Bandung, Indonesia. The berries were grind using dry mill blender (Panasonic MX -GM1011, Singapore) and sieved into a fine powder with the size ranged from 0.40 to $0.55 \mathrm{~mm}$. The powder was then immersed separately in absolute methanol and ethanol with the ratio of 1:10 at room temperature. Post 7 days of immersion, each of the mixture was filtered using Whatman filter paper No. 1 and concentrated using rotary vacuum evaporator (Heidoph VV2011, Schwabach, Germany) at $50^{\circ} \mathrm{C}$ and $120 \mathrm{rpm}$. To obtain a concentration of $10 \%$, the extract $(100 \mathrm{mg} / \mathrm{mL})$ was prepared by dissolving the extract in $100 \%$ dimethylsulfoxide (DMSO) (RandM Marketing, Essex, UK). The extract was then further diluted with sterile distilled water at $1: 10(\mathrm{v} / \mathrm{v})$ ratio to obtain $10 \mathrm{mg} / \mathrm{mL}$ of stock solution. The diluted extract was stored at $4^{\circ} \mathrm{C}$ prior to use.

\subsection{Inoculum (conidia) preparation}

A 7-day old fungi culture was harvested and rinsed into a flask containing $20 \mathrm{~mL}$ of sterile saline solution $(0.85 \% \mathrm{NaCl})$. The flask was then agitated at $200 \mathrm{rpm}$ at $30^{\circ} \mathrm{C}$ for $2 \mathrm{hrs}$ to break down the mycelial structure of the fungi. The suspension was then filtered through cotton wool to remove the debris. The concentration of the inoculums was adjusted to achieved the yield approximately $10^{4} \mathrm{CFU} / \mathrm{mL}$ using hemocytometer (Barrera-Necha et al., 2008).

\subsection{Disc diffusion assay}

Disc diffusion method adopted from Birhanu et al. (2014) was applied to the methanolic P. cubeba L. extract. A $100 \mu \mathrm{L}$ of prepared inoculum $\left(10^{4} \mathrm{CFU} / \mathrm{mL}\right)$ was spread uniformly onto PDA using a sterile cotton swab. The sterile paper disc impregnated with $10 \mu \mathrm{L}$ of $10 \mathrm{mg} / \mathrm{mL} P$. cubeba L. extract was then placed on top of the agar media. The positive and negative controls used in this study were $10 \mathrm{mg} / \mathrm{mL}$ of miconazole solution and 10\% DMSO, respectively. The plate was then incubated upright for $48 \mathrm{hrs}$ at $30^{\circ} \mathrm{C}$. The clear inhibition zones surrounding the disc were then measured in $\mathrm{mm}$.

\subsection{Determination of minimum inhibitory concentration} (MIC) and minimum fungicidal concentration (MFC)

MIC was determined according to the technique described by Clinical and Laboratory Standards Institute (2012). The test was performed in 96-well microtiter plate using two-fold standard broth microdilution method with the inoculums were adjusted at approximately $10^{4}$ CFU/mL. Column 1 of the wells was filled with $200 \mu \mathrm{L}$ of potato dextrose broth (PDB) (Difco, Sparks, Maryland, United States) which served as negative control. Column 2 acts as positive control, which filled with $100 \mu \mathrm{L}$ medium and $100 \mu \mathrm{L}$ of inoculums. The microdilution was performed at concentration of the methanolic extract ranged from $5.000 \mathrm{mg} / \mathrm{mL}$ in column 12 to $0.009 \mathrm{mg} / \mathrm{mL}$ in column 3 . The microtiter plate was then incubated at $30^{\circ} \mathrm{C}$ for $48 \mathrm{hrs}$. MFC was performed by subculturing $10 \mu \mathrm{L}$ of the suspension from each of the wells of the microtiter plates onto PDA and incubated at 
$30^{\circ} \mathrm{C}$ for $48 \mathrm{hrs}$.

\subsection{Inhibition conidial germination assay}

The method was performed according to the techniques described by Rukayadi and Hwang (2007) and Jin et al. (2004) with slight modifications. P. cubeba L. extract at $0 \times \operatorname{MIC}(0.000 \mathrm{mg} / \mathrm{mL}), 0.5 \times \operatorname{MIC}(0.625$ $\mathrm{mg} / \mathrm{mL}), 1 \times$ MIC $(1.250 \mathrm{mg} / \mathrm{mL}), 2 \times \operatorname{MIC}(2.500 \mathrm{mg} /$ $\mathrm{mL})$, and $4 \times \mathrm{MIC}(5.000 \mathrm{mg} / \mathrm{mL})$ were prepared and added to PDB containing approximately $10^{4} \mathrm{CFU} / \mathrm{mL}$ of fungi inoculums suspension until achieve the final volume of $1 \mathrm{~mL}$. The suspension was then incubated at $30^{\circ} \mathrm{C}$ for $24 \mathrm{hrs}$. Post incubation, the culture was thoroughly mixed using vortex before spreading $100 \mu \mathrm{L}$ of the fungi onto PDA plates. The plates were then incubated for $48 \mathrm{hrs}$ at $30^{\circ} \mathrm{C}$ prior colony counting and calculation of conidial germination inhibition percentage.

\subsection{In vivo assay of P. cubeba L. extract in tomato, grapes and lemon}

The assay was performed on wounded tomato, grapes and lemon by artificially inoculated $G$. candidum, $P$. citrinum and $T$. hirsuta isolates, respectively, as described by Liu et al. (2009). Seven fruits each were selected at similar stage of ripening, similar size, and visibly free from disease prior to dipping in $1 \%$ of Sodium Hypochlorite (NaOCL) ( $\mathrm{R}$ and M Marketing, Essex, UK) for $2 \mathrm{~min}$. The fruits were then rinsed with sterile distilled water and air dried inside the laminar flow. After that, the wounds were inflicted on the surface of the fruits with $2 \mathrm{~mm}$ deep $\mathrm{x} 5 \mathrm{~mm}$ width by using cork borer for uniform size before $20 \mu \mathrm{L}$ of the fungi inoculums were introduced. Post $10 \mathrm{~min}, 30 \mu \mathrm{l}$ of tap water, sterile distilled water, $0.05 \%, 0.50 \%$, and $5.00 \%$ of $P$. cubeba L. extract were pipetted into each of the wound. Sodium benzoate $\left(\mathrm{Na}_{2} \mathrm{C}_{5} \mathrm{O}_{7}\right)$ was used as positive control and $10 \%$ DMSO was used as negative control. All treated fruits were sealed in a sterile plastic container and incubated at $30^{\circ} \mathrm{C}$ with high humidity $(98 \%)$. The lesions of wounded samples were observed and the size of the lesion was measured post seven days of incubation.

\subsection{Statistical analysis}

All results were replicated two or three times with triplicates $(n=2 \times 3 / n=3 \times 3)$ for each treatment and the data were expressed as a mean \pm standard deviation. One-way analysis of variance (ANOVA) was performed using Minitab ${ }^{\circledR}$ Version 16 for Windows (Minitab Inc., USA) followed posthoc Tukey's test for means separation $(p<0.05)$.

\section{Results and discussion}

The methanolic and ethanolic extraction of $P$. cubeba L. berries by normal soaking method resulted with $21.0 \pm 0.1 \%$ and $18 \pm 0.1 \%$ recovery yields, respectively. Higher recovery yield was obtained from methanolic extract than ethanolic extract. According to Do et al. (2014), high extraction yield result usually obtained by high polarity solvent used in the extraction. As in this study, the polarity values for both solvents were 0.762 and 0.654 , for methanol and ethanol respectively. In comparison between methanolic extract, study by Choi and Hwang (2003) have shown $15.5 \%$ of recovery yield using $80.0 \%$ methanol as a solvent for 24 $\mathrm{h}$ of soaking period. The difference was most probably due to the soaking plant duration. As in this study, the berries were soaked in higher concentration of methanol and longer soaking duration. According to Efthymiopoulos et al. (2019), the extraction within short period of time period does not permit sufficient time for the solvent to recirculate the extract of total available oil in plant extract compounds. The statement also supported by previous study which asserted that the longer the solvent-sample soaked duration, the more efficient the extraction (Lawson et al., 2010).

The disc diffusion assay was performed to screen the capability of antifungal activity of $P$. cubeba L. extract against $G$. candidum, $P$. citrinum and T. hirsuta isolates. The inhibition zones of methanolic and ethanolic extracts of $P$. cubeba L. against the fungal isolates were presented in Table 1. Based on the findings, the methanolic extract showed higher inhibition zone compared to the ethanolic extract for all the tested isolates. Statistically, the significant different of the inhibition zone was seen in G. candidum and T. hirsuta between both solvents $(p<0.05)$. Between fungal species, the inhibition zone for $G$. candidum and $P$. citrinum shows no significant difference $(p>0.05)$ for both solvents. This is most probably due to the different of growing pattern for both fungi between T. hirsuta. Fungi of $G$. candidum and $P$. citrinum are fast growing colony on PDA media (Tiwari et al., 2011; Ma et al., 2018). In other study, the antifungal activity of essential oil $P$. cubeba L. extract also have shown $7.0 \mathrm{~mm}$ and $7.5 \mathrm{~mm}$ inhibition zone against Fusarium oxysporum and Alternaria porri respectively (Pawar and Thaker, 2007). Higher inhibition zone of methanolic extract also have been reported by Rukayadi et al. (2013) with $22.0 \mathrm{~mm}$ against Candida albicans.

In this study, disc diffusion assay function as initial antifungal screening of $P$. cubeba $\mathrm{L}$. extract. According to Othman et al. (2011), the test is not optimal to fully access of antifungal activity due to the lack of efficiency 
of hydrophobicity compound in extract to diffuse into agar media since the extract was hindered with the pore of disc paper. Therefore, MIC and MFC were conducted to further access of antifungal activity. The methanolic extract was selected to proceed with the next test study as it provide wider range of inhibition zone compared to the methanolic extract.

Table 1. Average inhibition zone of P. cubeba L. extract against G. candidum (TMa 001), P. citrinum (GRd 001) and T. hirsuta (LMd 001).

\begin{tabular}{ccc}
\hline \multirow{2}{*}{$\begin{array}{c}\text { Fungal } \\
\text { isolates }\end{array}$} & \multicolumn{2}{c}{ Inhibition zone $(\mathrm{mm})$} \\
\cline { 2 - 3 } & \multicolumn{2}{c}{ Solvents } \\
\cline { 2 - 3 } TMa 001 & $8.10 \pm 0.80^{\mathrm{Ab}}$ & $7.26 \pm 0.20^{\mathrm{Bb}}$ \\
GRd 001 & $7.67 \pm 0.90^{\mathrm{Ab}}$ & $7.13 \pm 0.20^{\mathrm{Ab}}$ \\
LMd 001 & $18.30 \pm 3.00^{\mathrm{Aa}}$ & $13.80 \pm 1.40^{\mathrm{Ba}}$ \\
\hline
\end{tabular}

Values are expressed as mean \pm standard deviation. Values with different capital alphabet superscripts in the same column are significantly different $(p<0.05)$ while values with different letter superscripts in the same row are significantly different $(p<0.05)$.

MIC was interpreted as the lowest concentration of antifungal agent to inhibit the growth of tested fungi compared to control (Rukayadi and Hwang, 2007). Whereas, MFC interpreted as minimum concentration of antifungal agent required to kill tested fungi. The results for MIC and MFC values for all the tested fungal isolates were presented in Table 2. Based on the findings, the methanolic $P$. cubeba L. extract required higher concentration at $1.250 \mathrm{mg} / \mathrm{mL}$ and $2.500 \mathrm{mg} / \mathrm{mL}$ to express their fungistatic and fungicidal effects respectively against $G$. candidum compared to the other two isolates. The antifungal activity of the extract was more effective against $T$. hirsuta followed by $P$. citrinum. According to Mohamed et al. (2014), high polarity of methanol solvent is effective to extract different types of sesquiterpenoids that determined the bioactivity of the extract. Monoterpenes and sesquiterpenes were responsible to the antibacterial activity of $P$. cubeba L. extract, however, for antifungal effects, the phytochemical contents of the methanolic extract such as alkaloid, lignin and terpenes were responsible for the activities.

Table 2. MIC and MFC of methanolic P. cubeba L. extract against G. candidum (TMa 001), P. citrinum (GRd 001) and T. hirsuta (LMd 001).

\begin{tabular}{ccc}
\hline Fungal isolates & MIC $(\mathrm{mg} / \mathrm{mL})$ & MFC $(\mathrm{mg} / \mathrm{mL})$ \\
\hline TMa 001 & 1.25 & 2.5 \\
GRd 001 & 0.625 & 1.25 \\
LMd 001 & 0.039 & 0.078 \\
\hline
\end{tabular}

The inhibition conidial germination assay was conducted to further determine the antifungal activity of $P$. cubeba $\mathrm{L}$. extract by increasing the concentration of the MIC value. The graph for inhibition conidial germination for all the tested isolates were plotted and presented in Figure 1. Based on the graph, the conidial inhibition of G. candidum gradually increased with the increase of $P$. cubeba L. extract concentration. At $0.5 \times$ MIC, $36.0 \%$ of the conidia were inhibited. Between $1 \times$ MIC to $2 \times \mathrm{MIC}$, the conidial germination slightly decreased. However, $80.3 \%$ of the conidia were inhibited at $2 \times$ MIC. At $4 \times$ MIC, almost all of the conidia were killed. For P. citrinum, nearly similar with G. candidum, $35.3 \%$ of the conidial growth was inhibited at $0.5 \times$ MIC. Slight decrease in conidial germination was seen between $1 \times$ MIC and $2 \times$ MIC. However, in comparison with $G$. candidum, the extract at $4 \times$ MIC was not enough to completely inactivate $P$. citrinum. For $T$. hirsuta, $27.6 \%$ of the conidia were inhibited after incubation with $0.5 \times$ MIC. Slight conidial inhibition was seen between the application of $0.5 \times \mathrm{MIC}$ and $1 \times$ MIC. However, $33.0 \%$ of conidia were inhibited at $2 \times$ MIC. At $4 \times$ MIC, $78.4 \%$ of the conidial germinations were inhibited. Even though, the extract at $4 \times$ MIC did not completely kill all the conidia of $T$. hirsuta, however, more than $70.0 \%$ of the conidial germination was inhibited at $0.156 \mathrm{mg} / \mathrm{mL}$, which is the lowest concentration at $4 \times$ MIC compared to other tested fungal isolates. Based on the findings, P. cubeba L. extract exhibited higher ability to inhibit the fungal conidia germination at high concentration. For all the three isolates, more than $70.0 \%$ of the germinations were inhibited at the maximum tested concentration.

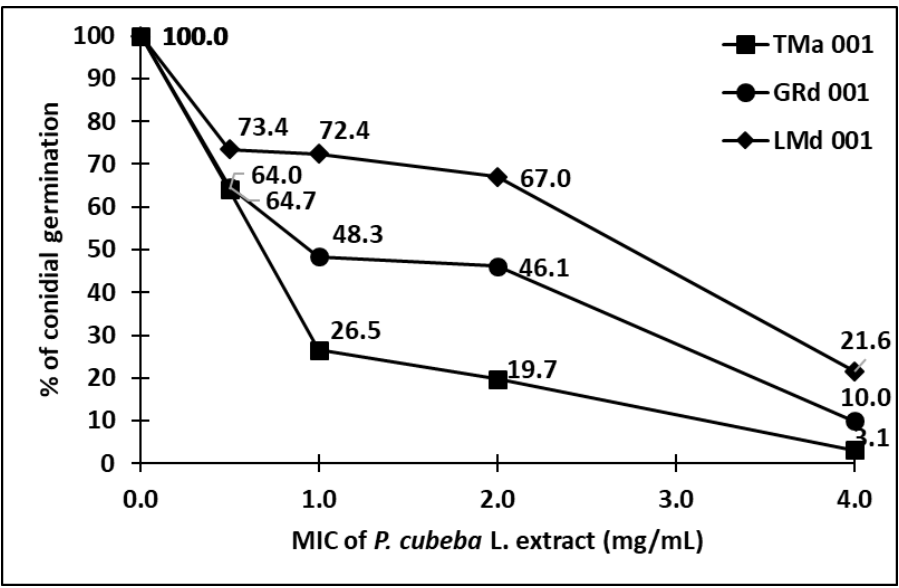

Figure 1. Effect of $P$. cubeba L. extract on conidial germination of G. candidum (TMa 001), P. citrinum (GRd 001) and T. hirsuta (LMd 001) at different MIC concentrations.

The presence of hyphal elements in tissue of filamentous fungi is a morphological form of infected fungi in vivo (Guarro et al., 1997). Even though study proved most pathogenic fungi are in hyphal form, most research in antifungal activity is analyzed by spore germination assay (Espeniel-Ingroff, 2001). However, The National Committee for Clinical Laboratory Standards (NCCLS) has proposed standardized 
procedure for conidial suspension preparation for antifungal activity study. According to Wendland (2001), conidial germination undergo four stage of process; (1) breakage of dormant spore initiate the spore formation, (2) germ spherical forming in isotropic growth phase, (3) polarization of marked site with emergence of germ tube and lastly (4), maintenance of polar hyphal growth and stimulate subsequent event started with cytokinesis to for, multicellular hyphae. Study by Ruiz et al. (2016) mentioned that, plant extract concentration above MIC showed inhibition of conidial germination by hindering isotropic growth, polarization stage and hyphal growth while complete inhibition of conidial germination achieved when concentration of the extract above the MFC values.

In vivo assay was performed onto the tomato, grape and lemon to further determine the antifungal effectiveness of the tested plant extract. The in vivo evaluation was applicable in various techniques (Liu et al., 2009; Svecova, 2010; Prakash et al., 2012). In this study, the experiment adopted the technique by Xing et al. (2012) and Fieira et al. (2013) by artificially wounded the fruits and intentionally inoculated it with the tested fungi to determine the antifungal capability of $P$. cubeba L. Figure 2 shows the post seven day lesions diameter of artificially wounded tomato, grapes and lemon that has been inoculated with G. candidum, P. citrinum and $T$. hirsuta, treated with different treatments, respectively. Based on the results, smaller lesion diameter was measured on the samples treated with $P$. cubeba extract compared to the negative control (10.00\% DMSO). The bigger lesion diameter size suggested lesser antifungal effect of the extract against the tested spoilage fungi. For G. candidum, the smaller lesion diameter was recorded in the samples treated with $0.50 \%$ extract concentration followed by $5.00 \%$ and $0.05 \%$ with $26.33 \mathrm{~mm}, 34.17$ $\mathrm{mm}$ and $41.17 \mathrm{~mm}$, respectively. In comparison to $P$. citrinum, the samples treated with $5.00 \%$ and $0.50 \%$ extract concentration show similar lesion diameter at $5.17 \mathrm{~mm}$ and followed by $0.05 \%$ at $5.50 \mathrm{~mm}$. For $T$. hirsuta, the smallest lesion diameter, at $5.50 \mathrm{~mm}$ was measured in the samples treated with the highest concentration of the $P$. cubeba L. extract. For the samples treated with tap water and sterilized distilled water, the lesion diameter was recorded bigger than the positive control (1.00\% sodium benzoate) post 7 days storage at $98.00 \%$ humidity environment. Basically, the findings suggested that washing fruits with tap water as well as sterilized distilled water will hasten the growth of spoilage fungi especially on the fruits that physically injured during handing process at any line of supply chain.

For tomatoes, the ideal concentration to exhibit the antifungal activity of the extract against $G$. candidum was recorded in $0.50 \%$ concentration compared to the higher tested concentration. The study showed inconsistency of the antifungal activity of the extract at high concentration. This is most probably due to the biochemical interaction between constituents of the extracts with the chemical composition in the food system. At high concentration, some plants may develop phytotoxicity. Phytotoxicity is an apparent discoloration damage that is induced on the cuticle or skin of fruits (Amiri et al., 2008). According to Svecova et al. (2016), phytotoxicity effects must be considered when applying high concentration of the extract especially as natural preservative from the medicinal plant. A study done by Svecova (2010) also has recommended to apply lower concentration of the plant extract frequently in order to reduce the phytotoxicity effect as well as to improve the antifungal action. In another study, Amiri et al. (2008) also mentioned that combination of plant extract with other substances like lecithin can reduce the phytotoxicity effect in fruits such as eugenol on the apple's cuticle.

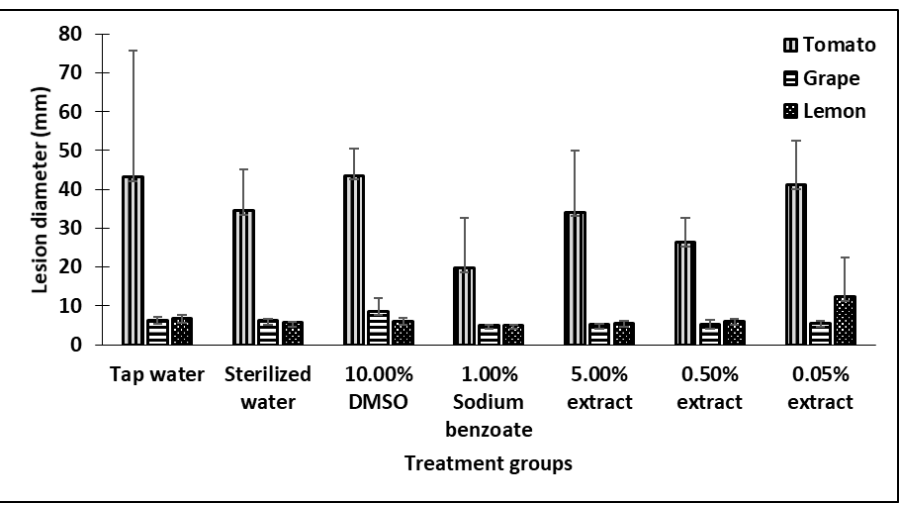

Figure 2. Diameter of lesion of artificially wounded tomato inoculated with G. candidum (TMa 001), grapes inoculated with P. citrinum (GRd 001) and lemon inoculated with $T$. hirsuta (LMd 001) in different treatment groups.

For grapes, the measured lesion diameter for $0.50 \%$ and $5.00 \%$ extract concentrations against $P$. citrinum were almost similar with the samples treated with $1.00 \%$ sodium benzoate that possess as positive control. Sodium benzoate is one of the synthetic preservatives that commonly added in food commodities to extend the shelf life of the food product. The application of the preservative may prevent potential damage that leads to reduce market value and food wastage (Knoche and Lang, 2017). For grapes, the easily penetrable thin skin with high nutrient value creates a hostile environment for the microorganism to grow. Fruit skin failure associated with a number of disorders including shriveling, cracking, russeting, and skin spots can occur if the fruits were not protected. As in this study, the application of $P$. cubeba L. extract between the range of $0.50 \%$ to $5.00 \%$ concentration were as good as the commercial synthetic preservative in providing antifungal protection against $P$. 
citrinum for at least 7 days at 98\% humidity environment. Another study by Xing et al. (2012) has also shown the effective antifungal effects against $P$. citrinum on orange and jujube fruits by using $3.00 \%$ of clove oil.

For lemon, the smallest lesion diameter was recorded in the samples treated with $5.00 \% P$. cubeba L. extract concentration. By lowering the concentrations of the extract, lesser antifungal effect against $T$. hirsuta were observed. The effect of the extracts against $T$. hirsuta at the highest tested concentration nearly acting as the selected positive control. Application of the extract at $5.00 \%$ concentration can be recommended to replace the synthetic preservative in lemon. However, in comparison with the other selected host, the deteriorating effect of lemon against fungal infection was minimal due to the presence of thick skin of the outer layer of matured fruit. The skin created large barrier for the microorganism to attack the lemon fruits at the storage line (Arendse et al., 2018). In addition, the high acidity contents in the lemon fruit becomes a weapon for the lemon fruit to protect themselves from the foreign microorganism (Shen et al., 2017).

\section{Conclusion}

In conclusion, the antifungal activity of methanolic $P$. cubeba L. extract was effective against $G$. candidum, $P$. citrinum and $T$. hirsuta, and its application in tomatoes, grapes and lemon suppressed the growth of the selected fungi. The extract at the optimum concentration can be used as natural antifungal agents of choice for the replacement of synthetic preservative. Various types of natural antifungal agents will help in reducing the usage of chemical fungicide, which may lead to adverse and deteriorating health effects of prolong consumption.

\section{Conflict of Interest}

Authors declare no conflict of interest.

\section{References}

Amiri, A., Dugas, R., Pichot, A.L. and Bompeix, G. (2008). In vitro and in vivo activity of eugenol oil (Eugenia caryophylata) against four important postharvest apple pathogens. International Journal of Food Microbiology, 126(1-2), 13-19. https:// doi.org/10.1016/j.ijfoodmicro.2008.04.022

Aneja, K.R., Joshi, R., Sharma, C. and Aneja, A. (2010). Antimicrobial efficacy of fruit extracts of two Piper species against selected bacterial and oral fungal pathogens. Brazilian Journal of Oral Sciences, 9(4), 421-426. https://doi.org/10.20396/bjos.v9i4.8641724
Arendse, E., Fawole, O.A., Magwaza, L.S. and Opara, U.L. (2018). Non-destructive prediction of internal and external quality attributes of fruit with thick rind: a review. Journal of Food Engineering, 217, 11 -23. https://doi.org/10.1016/j.jfoodeng.2017.08.009

Barrera-Necha, L.L., Bautista-Banos, S., FloresMoctezuma, H.E. and Estudillo, A.R. (2008). Efficacy of essential oils on the conidial germination, growth of Colletotrichum gloeosporioides (Penz.) Penz. and Sacc and control of postharvest diseases in papaya (Carica papaya L.). Plant Pathology Journal, 7(2), 174-178. https:// doi.org/10.3923/ppj.2008.174.178

Birhanu, S., Akhtar, M.S. and Muleta, D. (2014). Management of post-harvest fruit spoilage fungi by some potential spice extracts. Archives of Phytopathology and Plant Protection, 47(17), 21242140.

https:// doi.org/10.1080/03235408.2013.869891

Bos, R., Woerdenbag, H.J., Kayser, O., Quax, W.J., Ruslan, K. and Elfami. (2007). Essential oil constituents of Piper cubeba L. fils. from Indonesia. Journal of Essential Oil Research, 19(1), 14-17.

https://

doi.org/10.1080/10412905.2007.9699217

Cabral, L.C., Fernandez Pinto, V. and Patriarca, A. (2013). Application of plant derived compounds to control fungal spoilage and mycotoxin production in foods. International Journal of Food Microbiology, 166(1), 1-14. https://doi.org/10.1016/ j.ijfoodmicro.2013.05.026

Choi, E.M. and Hwang, J.K. (2003). Investigations of anti-inflammatory and antinociceptive activities of Piper cubeba, Physalis angulata and Rosa hybrida. Journal of Ethnopharmacology, 89(1), 171-175. https://doi.org/10.1016/S0378-8741(03)00280-0

Cilerdzic, J., Stajic, M., Vukojevic, J., Duletic-Lausevic, S. and Knezevic, A. (2011). Potential of Trametes hirsuta to produce ligninolytic enzymes during degradation of agricultural residues. BioResources, 6 (3), 2885-2895. https://doi.org/10.15376/ biores.6.3.2885-2895

Clinical and Laboratory Standards Institute. (2012). Reference Method for Performance Standards for Antimicrobial Disk Susceptibility Tests, CLSI Document M02-A11. $11^{\text {th }}$ ed. USA: Clinical and Laboratory Standards Institute.

Do, Q.D., Angkawijaya, A.E., Tran-Nguyen, P.L., Huynh, L.H., Soetaredjo, F.E., Ismadji, S. and Ju, Y.H. (2014). Effect of extraction solvent on total phenol content, total flavonoid content, and antioxidant activity of Limnophila aromatica. Journal of Food and Drug Analysis, 22(3), 296-302. 
https://doi.org/10.1016/j.jfda.2013.11.001

Efthymiopoulos, I., Hellier, P., Ladommatos, N., Kay, A. and Mills-Lamptey, B. (2019). Effect of solvent extraction parameters on the recovery of oil from spent coffee grounds for biofuel production. Waste and Biomass Valorization, 10(2), 253-264. https:// doi.org/10.1007/s12649-017-0061-4

Espeniel-Ingroff, A. (2001). Germinated and nongerminated conidial suspensions for testing of susceptibilities of Aspergillus spp. to amphotericin B. Antimicrobial Agents and Chemotherapy, 45(2), 18-21. https://doi.org/10.1128/AAC.45.2.605607.2001

Esperandim, V.R., Da Silva Ferreira, D., Sousa Rezende, K.C., Magalhaes, L.G., Medeiros Souza, J., Pauletti, P.M. and Andrade-Silva, M.L. (2013). In vitro antiparasitic activity and chemical composition of the essential oil obtained from the fruits of Piper cubeba. Planta Medica, 79(17), 1653-1655. https:// doi.org/10.1055/s-0033-1351022

Fieira, C., Oliveira, F., Calegari, R.P., Machado, A. and Coelho, A.R. (2013). In vitro and in vivo antifungal activity of natural inhibitors against Penicillium expansum. Ciencia e Tecnologia de Alimentos, 33 (1), 40-46. https://doi.org/10.1590/S010120612013000500007

Gram, L., Ravn, L., Rasch, M., Bruhn, J.B., Christensen, A.B. and Givskov, M. (2002). Food spoilageinteractions between food spoilage bacteria. International Journal of Food Microbiology, 78(12), 79-97. https://doi.org/10.1016/S0168-1605(02) 00233-7

Guarro, J., Llop, C. and Aguilar, C. (1997). Comparison of in vitro antifungal susceptibilities of conidia and hyphae of filamentous fungi. Antimicrobial Agents and Chemotherapy, 41(12), 2760-2762. https:// doi.org/10.1128/AAC.41.12.2760

Gustavsson, J., Cederberg, C., Sonesson, U., van Otterdijk, R. and Meybeck, A. (2011). Global Food Losses and Food Waste: Extent, Causes and Prevention. Italy: Food and Agricutural Organization.

Hussein, G., Miyashiro, H., Nakamura, N., Hattori, M., Kakiuchi, N. and Shimotohno, K. (2000). Inhibitory effects of Sudanese medicinal plant extracts on hepatitis C virus (HCV) protease. Phytotherapy Research, 14(7), 510-516. https:// doi.org/10.1002/1099-1573(200011)14:7.510

Ismail, M. and Zhang, J. (2004). Post-harvest citrus diseases and their control. Outlooks on Pest Management, 15(1), 29-35. https:// doi.org/10.1564/15feb12
Jin, J.K., Adams, D.O., Ko, Y., Yu, C.W. and Lin, C.H. (2004). Aviglycine and propargylglycine inhibit conidial germination and mycelial growth of Fusarium oxysporum f. sp. luffae. Mycopathologia, 158(3), 369-375. https://doi.org/10.1007/s11046-004 $-2225-6$

Kalyoncu, F., Tamer, A.U. and Oskay, M. (2005). Determination of fungi associated with tomatoes (Lycopersicum esculentum M.) and tomato pastes. Plant Pathology Journal, 4, 146-149.

Knoche, M. and Lang, A. (2017). Ongoing growth challenges fruit skin integrity. Critical Reviews in Plant Sciences, 36(3), 190-215. https:// doi.org/10.1080/07352689.2017.1369333

Latorre, B.A., Viertel, S.C. and Spadaro, I. (2002). Severe outbreaks of bunch rots caused by Rhizophus stolonifer and Aspergillus niger on table grapes in Chile. Plant Disease, 86(7), 815. https:// doi.org/10.1094/PDIS.2002.86.7.815C

Lawson O.S., Oyewuni A., Ologunagba F.O. and Ojoma A.O. (2010). Evaluation of the parameters affecting the solvent extraction of soybean oil. APRN Journal of Engineering and Applied Sciences, 5(10), 51-55.

Liu, X., Wang, L.P., Li, Y.C., Li, H.Y., Yu, T. and Zheng, X.D. (2009). Antifungal activity of thyme oil against Geotrichum citri-aurantiiin vitro and in vivo. Journal of Applied Microbiology, 107(5), 1450$1456 . \quad$ https://doi.org/10.1111/j.13652672.2009.04328.x

Ma, W., Zhang, Y., Wang, C., Liu, S. and Liao, X. (2018). A new disesae of strawberry, fruit rot, caused by Geotrichum candidum in China. Plant Protection Science, 54(2), 92-100. https:// doi.org/10.17221/76/2017-PPS

Mohamed, A.A., Ali, S.I., EL-Baz, F.K., Hegazy, A.K. and Kord, M.A. (2014). Chemical composition of essential oil and in vitro antioxidant and antimicrobial activities of crude extracts of Commiphora myrrha resin. Industrial Crops and Products, 57, 10-16. https://doi.org/10.1016/ j.indcrop.2014.03.017

Nahak, G. and Sahu, R.K. (2011). Phytochemical evaluation and antioxidant activity of Piper cubeba and Piper nigrum. Journal of Applied Pharmaceutical Science, 1(8), 153-157.

Othman, M., Loh, H.S., Wiart, C., Khoo, T.J., Lim, K.H. and Ting, K.N. (2011). Optimal methods for evaluating antimicrobial activities from plant extracts. Journal of Microbiological Methods, 84(2), 161-166. https://doi.org/10.1016/ j.mimet.2010.11.008

Palou, L., Crisosto, C.H. and Garner, D. (2007). 
Combination of postharvest antifungal chemical treatments and controlled atmosphere storage to control gray mold and improve storability of 'Wonderful' pomegranates. Postharvest Biology and Technology, 43(1), 133-142. https://doi.org/10.1016/ j.postharvbio.2006.08.013

Parmar, V.S., Jain, S.C., Bisht, K.S., Jain, R., Taneja, P., Jha, A. and Boll, P.M. (1997). Phytochemistry of the genus Piper. Phytochemistry, 46(4), 597-673. https:// doi.org/10.1016/S0031-9422(97)00328-2

Pawar, V.C. and Thaker, V.S. (2007). Evaluation of the anti-Fusarium oxysporum f. sp cicer and antiAlternaria porri effects of some essential oils. World Journal of Microbiology and Biotechnology, 23(8), 1099-1106. https://doi.org/10.1007/s11274-006-9339 $-6$

Pitt, J.I. and Hocking, A.D. (2009). Fungi and Food Spoilage. $3^{\text {rd }}$ ed. New York: Springer.

Prakash, B., Singh, P., Kedia, A. and Dubey, N.K. (2012). Assessment of some essential oils as food preservatives based on antifungal, antiaflatoxin, antioxidant activities and in vivo efficacy in food system. Food Research International, 49(1), 201208. https://doi.org/10.1016/j.foodres.2012.08.020

Rezende, K.C.S., Lucarini, R., Simaro, G.V., Pauletti, P.M., Januario, A.H., Esperandim, V.R., Martins, C.H.G., Silva, M.A., Cunha, W.R., Bastos, J.K. and Silva, M.L.A.E. (2016). Antibacterial activity of (-)cubebin isolated from Piper cubeba and its semisynthetic derivatives against microorganisms that cause endodontic infections. Brazilian Journal of Pharmacognosy, 26(3), 296-303. https:// doi.org/10.1016/j.bjp.2015.12.006

Ruiz, M.D.P., Ordonez, R.M., Isla, M.I. and Sayago, J.E. (2016). Activity and mode of action of Parastrephia lepidophylla ethanolic extracts on phytopathogenic fungus strains of lemon fruit from Argentine Northwest. Postharvest Biology and Technology, 114, 62-68. https://doi.org/10.1016/ j.postharvbio.2015.12.003

Rukayadi, Y. and Hwang, J. (2007). In vitro antimycotic activity of xanthorrhizol isolated from Curcuma xanthorrhiza Roxb. Against opportunistic filamentous fungi. Phytotherapy Research, 21(5), 434-438. https://doi.org/10.1002/ptr.2092

Rukayadi, Y., Lau, K.Y., Zainin, N.S., Zakaria, M. and Abas, F. (2013). Screening antimicrobial activity of tropical edible medicinal plant extracts against five standard microorganisms for natural food preservative. International Food Research Journal, 20(5), 2905-2910.

Samuel, O. and Orji, M.U. (2015). Fungi associated with the spoilage of post-harvest tomato fruits sold in major markets in Awka, Nigeria. Universal Journal of Microbiology Research, 3, 11-16. https:// doi.org/10.13189/ujmr.2015.030201

Shakeel, F., Alam, P., Anwer, M.K., Alanazi, S.A., Alsarra, I.A. and Alqarni, M.H. (2019). Wound healing evaluation of self-nanoemulsifying drug delivery system containing Piper cubeba essential oil. 3 Biotech, 9, 82. https://doi.org/10.1007/s13205019-1630-y

Sheikh, M., Malik, A.R., Meghavanshi, M.K. and Mahmood, I. (2012). Studies on some plant extracts for their antimicrobial potential against certain pathogenic microorganisms. American Journal of Plant Sciences, 3(2), 209-213. https:// doi.org/10.4236/ajps.2012.32025

Shen, P., Walker, G.D., Yuan, Y., Reynolds, C., Stacey, M.A. and Reynolds, E.C. (2017). Food acid content and erosive potential of sugar-free confections. Australian Dental Journal, 62(2), 215222. https://doi.org/10.1111/adj.12498

Svecova, E. (2010). Control of phytopathogenic fungi in horticultural crops by natural plant extracts. (Doctoral dissertation). Italy: Universita degli Studi della Tuscia.

Svecova, E., Colla, G. and Crino, P. (2016). Antifungal activity of Boerhavia diffusa L. extract against Phytophthora spp. in tomato and pepper. European Journal of Plant Pathology, 148, 27. https:// doi.org/10.1007/s10658-016-1065-9

Tiwari, K.L., Jadhav, S.K. and Kumar, A. (2011). Morphological and molecular study of different Penicillium species. Middle-East Journal of Scientific Research, 7(2), 203-210.

Tournas, V.H. and Katsoudas, E. (2005). Mould and yeast flora in fresh berries, grapes and citrus fruits. International Journal of Food Microbiology, 105(1), 11-17. https://doi.org/10.1016/ j.ijfoodmicro.2005.05.002

Wendland, J. (2001). Comparison of morphogenetic networks of filamentous fungi and yeast. Fungal Genetics and Biology, 34(2), 63-82. https:// doi.org/10.1006/fgbi.2001.1290

Xing, Y., Xu, Q., Li, X., Che, Z. and Yun, J. (2012). Antifungal activities of clove oil against Rhizopus nigricans, Aspergillus flavus and Penicillium citrinum in vitro and in wounded fruit test. Journal of Food Safety, 32(1), 84-93. https://doi.org/10.1111/ j.1745-4565.2011.00347.x 